\title{
Quidditism and Contingent Laws
}

\begin{abstract}
According to contingentism, laws of nature hold contingently. An objection to contingentism is that it implies quidditism, and therefore inherits its implausible consequences. This paper argues that this objection is misguided. Understood one way, quidditism is not an implication of contingentism, hence even if it has implausible consequences, these are not relevant to contingentism. Understood another way, quidditism is implied by contingentism, but it is less clear if this version of quidditism has the same implausible consequences. Whatever the merits of contingentism, the argument from anti-quidditism is not successful in showing that it is false.
\end{abstract}

\section{Introduction}

We often attribute causal powers to natural properties (henceforth, properties). We say that being negatively charged causes a particle to repel other negatively charged particles, for example. But such attributions are derivative on the attributions of causal powers to the bearers of such properties. An interesting question is how we should understand the relationship between a property and the causal powers of its bearers. Whereas contingentism (e.g. Armstrong 1983) takes the relationship between properties and the causal powers of their bearers to be metaphysically contingent, necessitism (e.g. Shoemaker 1980; 1998; Bird 2007) holds that this relationship is metaphysically necessary. The central thesis of necessitism is that, necessarily, if certain properties are instantiated, then certain causal powers are held by the objects that instantiate these properties. A consequence of necessitism is that laws of nature are themselves metaphysically necessary: if properties are metaphysically inseparable from causal powers this way, and if laws of nature are meant to dictate how properties are linked to the causal powers of concrete objects, we should expect that laws, if there are any such things, should hold with metaphysical necessity. However, in 
the face of the prima facie plausibility of the view that the laws of nature could have been different from how they actually are, defenders of necessitism owe us an argument against such contingency. The target of this paper is one of these arguments, which I take to be particularly weak: the argument from anti-quidditism.

The argument from anti-quidditism has the following basic structure: contingentism implies quidditism, but quidditism is a highly implausible thesis; therefore, contingentism inherits the implausibility of quidditism, and hence should be rejected. In what follows, I will argue that this argument fails to problematise the contingency of laws of nature because of an equivocation of "quidditism". If we understand quidditism one way, contingentism doesn't imply quidditism, hence even if quidditism has implausible consequences, these are not relevant to contingentism. If we understand quidditism another way, contingentism implies quidditism, but it is less clear if this version of quidditism has these implausible consequences. Hence, I argue, whatever the merits of contingentism, the argument from antiquidditism is not successful in showing that it is false.

\section{The cardinality argument}

A philosopher who is moved by the argument from anti-quidditism is Mumford (2004). He argues that "a major shortcoming of [a contingentist] conception of laws is that it appears to have no likely way of avoiding the implication that laws could vary independently of properties. This entails a thesis that is called quidditism that seems highly undesirable" (ibid., p. 149). ${ }^{1}$ But, what is quidditism?

\footnotetext{
${ }^{1}$ Mumford calls this an "external", rather than "contingentist", conception of laws. This terminological difference is important in assessing Mumford's overall treatment of laws, as the
} 
The basic idea behind quidditism is that there are trans-world identity relations between properties and these trans-world identity relations depend on nothing more than the intrinsic nature of such properties. This implies that properties are metaphysically separable from their nomic roles, because the identity of a property is not fixed by, or dependent on, the nomic role that it plays. There is a problem with such a broad-brush way of formulating quidditism, but that problem is the reason why the argument from anti-quidditism fails. So please bear with me until I offer slightly more precise ways of understanding quidditism below.

In cashing out the alleged implausible consequences of both quidditism and contingentism, the argument that Mumford appeals to is originally from Black (2000). It goes as follows:

(i) According to quidditism, the number of the possible natural properties has to be an arbitrary one. $^{2}$ (I will explain the reasoning behind this premise below.)

(ii) It is an embarrassment to any theory of properties and/or laws if the theory implies that there is no such non-arbitrary number. ${ }^{3}$

externality of laws to properties leads to other problems for such laws, according to Mumford. As far as the arguments in this paper are concerned, this difference is negligible.

\footnotetext{
${ }^{2}$ For the quidditist, there is no "non-arbitrary answer to the question of how many (fundamental) qualities there are in the totality of possible worlds" (Mumford 2004, p. 152).

${ }^{3}$ This is "an embarrassment to any theory of laws that allows laws and properties to vary independently" (ibid., p. 152).
} 
(iiii) Therefore, quidditism should be rejected. ${ }^{4}$

Call this the cardinality argument. Now, the link between the cardinality argument and the argument form anti-quidditism is this. The latter assumes that quidditism, which is allegedly implied by contingentism, is an implausible thesis, and the former aims to spell out why quidditism is an implausible thesis. I now want to persuade you that the cardinality argument is simply irrelevant to the assessment of contingentism.

To see what is wrong with the cardinality argument, we must first distinguish between the following two theses, which are both committed to the metaphysical separability of properties and nomic roles, but in different ways:

(Q1) It is possible for the same natural property to have different nomic roles in different worlds.

(Q2) It is possible for two worlds to have exactly the same laws yet differ in some or all of their natural properties.

(Q1) and (Q2) are distinct theses, and this may be overlooked because of the broad-brush characterisation of quidditism that I mentioned above. ${ }^{5}(\mathrm{Q} 1)$ makes the nomic profile of

\footnotetext{
${ }^{4}$ The validity of the argument relies on suppressed premises that I need not make explicit.

${ }^{5}$ Bird (2007), who is also an opponent of quidditism, distinguishes two claims of quidditism. But he implies that reasons in favour of one should be reasons in favour of the other. He says: "If a [property] can lose a power with ease, it can also gain one" (ibid., p. 72). Bird's argument against (Q1) is an analogue of an argument against haecceitism (the view that trans-world identity of individuals doesn't require the sameness of any properties). Bird's argument (ibid., pp. 75-76) is that we have good reasons to think that individuals have essential properties---he does this by showing that Chisholm's
} 
properties contingent. (Q2) denies that nomic profiles individuate properties. So, as far as (Q2) is concerned, there could be different properties that play the exact same nomic roles. But (Q1) doesn't imply this. As far as (Q1) is concerned, it may well be the case that the same nomic role is played by the same property in every possible world where that nomic role is played at all. It is just that in some worlds where the actual nomic roles are not played, actual properties may play different nomic roles.

With this distinction made, now we can see that the argument that Mumford borrows from Black actually targets (Q2). ${ }^{6}$ Here is why: Black supports premise (i) by arguing that, in the quidditist picture, for any possible world $w$, there can always be another world which is exactly like $w$ with respect to its nomic structure (i.e., the same laws hold) but with different fundamental properties that $w$ has. Quidditism, according to how Black characterises it, allows that we could just replace a property $F$ in a nomic structure $N$ with another property

(1967) argument against essential properties isn't successful. Then he argues that "just as we should reject haecceitism we should reject quidditism [Q1], which we may do by allowing both particulars and properties to have essential properties" (2007, p. 75). Other authors who have highlighted the fact that in contemporary metaphysics "quidditism" is used to refer to different, but related, views are Locke (2012), Hildebrand (2016), and Smith (2016). Contrary to Bird, these latter authors think that some of these views are defensible; though neither appeals to the distinction between (Q1) and (Q2) to tackle the argument from anti-quidditism.

${ }^{6}$ In fact, Black's argument targets the conjunction of (Q2) and Lewis's (1986) modal realism. This renders the cardinality argument even weaker, given that contingentists need not be committed to Lewis's modal realism. In the case of Black, this can be excused because Black's original article is in fact a critical assessment of Lewis's overall metaphysics of properties and laws, rather than quidditism generally. In a way, Black's argument is ardently ad hominem, in a non-fallacious way. 
$F^{*}$, and there will be a world where $N$ holds with $F^{*}$ rather than $F$. Agreeing with Black, Mumford says that "for any number of (fundamental) properties you think there might be, the quidditist has no principled reason why there could not be one more than that number" $(2004$, p. 152). This is why Black and Mumford think that for quidditists, there is no non-arbitrary answer to the question of how many possible properties there are. ${ }^{7}$ If you want to say that there are $n$ possible properties, nothing stops you from also thinking that there are $n+1$ possible properties. But note that if this is indeed problematic, it is problematic for (Q2), not for (Q1).

However, contingentism is only committed to (Q1). This is because contingentism implies that the laws of the actual world could have failed to hold. It accepts that there could be worlds with the same properties of the actual world, yet with different laws. On this view, natural properties play different nomic roles in different possible worlds. Scenarios with two possible worlds with exactly the same nomic structure are not relevant to the hypothesis that laws are contingent. This is why a theory of contingent laws is committed to (Q1), but not to (Q2). It is true that intuitions that support one may support the other, and this might indeed be the reason why defenders of one tend to hold the other. But it is also important to note that intuitions that challenge one may not challenge the other. That is, there might be reasons why one is counterintuitive, whereas the same reasons don't render the other counterintuitive. I believe this is the case with (Q1) and (Q2).

What is the upshot of this for contingentism? Let me put it as a dilemma. On the one hand, if "quidditism" in (i) of the cardinality argument refers to the view that is expressed by (Q1),

\footnotetext{
${ }^{7}$ Once again (as per footnote 6), Black argues against Lewis, and his real worry with Lewis's quidditism and modal realism is that these two views, together, lead to the conclusion that there is no non-arbitrary answer to the question of how many worlds (rather than properties) there are.
} 
then (i) is simply false, therefore the cardinality argument is unsound. On the other hand, if "quidditism" in (i) refers to the view expressed by (Q2), then (i) may or may not be true (and the cardinality argument may or may not be sound), but the argument is simply irrelevant to contingentism. So, the cardinality argument is either unsound or otherwise irrelevant to the assessment of contingentism. Either way, opponents of contingentism shouldn't appeal to the cardinality argument.

\section{Conclusion}

I assessed argument from anti-quidditism as an argument against contingentism, and argued that it fails. In tackling this argument, I disambiguated between two theses---(Q1) and (Q2)--which both imply the metaphysical separability of properties and their nomic roles. But they do this in different ways. To the extent that quidditism is understood as (Q2), quidditism may or may not be problematic, but contingentism about laws is not committed to it. To the extent that quidditism is understood as (Q1), then the argument in question doesn't target contingentism.

\section{ACKNOWLEDGMENTS}

For comments on a recent version of this paper, many thanks to Martin Pickup and Nathan Wildman; for comments and discussion on related work, thanks to Jonas Christensen, Toby Friend, Neil McDonnell, Andrea Raimondi, and Tuomas Tahko.

\section{References}

Bird, A. (2007). Nature's Metaphysics. Oxford: Oxford University Press.

Black, R. (2000). Against Quidditism. Australasian Journal of Philosophy, 78(1): 87-104. 
Chisholm, R. (1967). Identity through Possible Worlds. Noûs, 1: 1-8.

Hildebrand, T. (2016). Two Types of Quidditism. Australasian Journal of Philosophy, 94: $516-532$.

Lewis, D. (1986). On the Plurality of Worlds. Oxford: Blackwell.

Locke, D. (2012). Quidditism without quiddities. Philosophical Studies, 160: 345-363.

Mumford, S. (2004). Laws in Nature. New York: Routledge.

Shoemaker, S. (1980). Causality and Properties. In P. van Inwagen, Time and Cause (pp. 109-135). Dordrecht: Reidel.

Shoemaker, S. (1998). Causal and Metaphysical Necessity. Pacific Philosophical Quarterly, 79(1): 59-77.

Smith, D. (2016). Quid Quidditism Est? Erkenntnis, 81:237-257.

Swoyer, C. (1982). The Nature of Natural Laws. Australasian Journal of Philosophy 60: 203-23. 